\title{
Achieving Youth Empowerment in UAE through Incorporating Entrepreneurial Skills in Technical Vocational Education and Training
}

\author{
Ghanim Alhajeri ${ }^{1}$ \\ ${ }^{1}$ Zoo and Aquarium Public Institution in Al Ain, Abu Dhabi, United Arab Emirates \\ Correspondence: Ghanim Alhajeri, Zoo and Aquarium Public Institution in Al Ain, Abu Dhabi, United Arab \\ Emirates.
}

Received: February 22, 2021

Accepted: March 24, 2021

Online Published: March 29, 2021

doi:10.5539/ibr.v14n4p101

URL: https://doi.org/10.5539/ibr.v14n4p101

\begin{abstract}
UAE government can stimulate the development of innovations by giving due emphasis on the promotion of entrepreneurship education in youth. Technical and Vocational Education and Training (TVET) would only succeed in UAE, when young individuals devise new technologies by using available resources, recruit and train the locals and manufactures products for both domestic and international consumption. This study emphasizes on the efforts made by the UAE government, particularly the government of Abu Dhabi for upgrading and expanding vocational education in collaboration with the private sector. An explorative study design is employed to review the need of the growth of vocational education in UAE with specific reference to Abu Dhabi. It also examines the recent efforts, undertaken in the vocational education sector in UAE and Abu Dhabi. Apparently, there is minimal evidence that technical and vocational education and training interventions are effective to provide employment for young people. The perception behind support and benefits, shared concepts of significance to offer entrepreneurship education.
\end{abstract}

Keywords: empowerment, entrepreneurial skills, technical vocational education and training, UAE

\section{Introduction}

The population of the seven emirates that constitute the United Arab Emirates (UAE) is approximately 9.4 million (6.4 million male and 3.1 million female). Considering this population size, it is the foremost responsibility of the UAE government to ensure growth and prosperity of its inhabitants, for which quality education plays an influential role (Al Hammadi, 2016). The education sector of UAE has earned a reputable position with respect to other sectors of the region. Almost $25 \%$ of its budget is allocated to the education sector to facilitate its inhabitant in achieving educational excellence (Raven, 2010). The estimated worth of the education sector is US\$7.31 billion, which is predicted to increase further with continuous rise in the demand of new private and public schools (Al Hammadi and Mohinuddin, 2016). Furthermore, the UAE government has made dedicated attempts to stimulate educational activities and enhance academic excellence by encouraging the private education providers and integrating educational activities to dissipate knowledge to the students (Wilkins, 2002). Thus, the UAE government has remained concerned and committed since its establishment regarding the provision of high quality general and vocational education to all major sectors for community development.

It has been established that, investment in vocational education sector by government is vital to human resource development and equips the residents with the essential employability skills and abilities (Asadullah and Ullah). It is based on dissipating the practical knowledge to the students as compared to the cut-throat learning (Al Hammadi, 2016). Likewise, an emphasis on entrepreneurship education is made that offers skills, motivation and relevant knowledge to the students for stimulating entrepreneurial success. Entrepreneurship involves wide range of analysis and activities that no one can encapsulate it as definitive (Ridge et al., 2015). This skill also helps an individual transform his notions into realities. Today India has the largest manpower in the world because it is in their national policy to invest in vocational education (Goel and Vijay, 2011). The Indian National Policy on Education, 1986 (modified in 1992) envisioned the introduction of rigorous, well-planned and systemic implementation of vocational training, and claimed that it will provide an alternative to tertiary education, enhance employability and help overcome the shortage of skilled manpower (Government of India, 1992). With increasing awareness, several countries through policies have successfully taken initiatives to invest and promote development of entrepreneurship among their citizens (Abhyankar, 2014; Schwanen, 2017; Vixathep, 2017). 
Therefore, UAE government can stimulate the development of innovations by giving due emphasis on the promotion of entrepreneurship education in youth. Technical and Vocational Education and Training (TVET) would only succeed in UAE, when young individuals devise new technologies by using available resources, recruit and train the locals and manufactures products for both domestic and international consumption (Jose, 2011). This is possible only if entrepreneurship education is incorporated into the TVET curricula, specifically at university level.

In the current era, possession of an educational certificate is not considered as a guarantee or approval for a job. In the modern era, traditional education must be supplemented with the essential vocational knowledge and skills necessary for self-employment (AlMunaiied and Sabbagh, 2011). The production capability and efficiency of self-reliant organization emerge from the integration of entrepreneurship education into TVET. In 2007, the UAE Government devised a strategy that urged the development of a high-quality education to fulfil international standards and the needs of the workplace. Moreover, it also focused on promoting vocational education and strengthening scientific research (Jose and Chacko, 2017). Recently in UAE, the higher secondary technical colleges have launched a summer program for 7th to 12th graders in the pretext of COVID-19 pandemic and the future high demand of healthcare auxiliaries (AlefEducation). The main responsibility lies on the government to ensure and enable Emirati educational institutions to boost and encourage entrepreneurship and innovativeness uniformly in the youth. This puts forth the question of this study i.e., how could an enabling environment be provided for the youth that would encourage and enhance entrepreneurship and innovativeness in education?

Therefore, the focus of this paper will be on the efforts made by the UAE government, particularly the government of Abu Dhabi for upgrading and expanding vocational education in collaboration with the private sector. The objective would be to practically homogenize the educational and workplace environments so that the youth do not feel they are crossing into unknown realm when they incorporate the two domains into their studies. The intensification of vocational training should be just one of the objectives of an enhanced association between the business and education sectors. The elevated collaboration, which will be envisioned in this study, would contribute in the development of internships, mentoring programs, research and development (R\&D) ventures and summer jobs that would significantly help the youth of UAE to increase and polish their skills. From the perspective of public education systems, there would be more openness to the pre-requisites of the labor market. It will be more opportune for young people to graduate with a capacity for entrepreneurship, innovation and marketable skills.

Another contribution envisioned by this study will be to create guidelines that would direct UAE government to provide more guidance on potential careers to youth right from an early age, more specifically at high school and university levels. In this way, the youth could benefit majorly from helpful information regarding different career choices and new horizons they may not have realized otherwise. The emphasis on this strategy is mandatory since labor market in 2040 will provide tech-based jobs that will completely replace the existing jobs. In this regard, the role of private sector will be vital as the ultimate job market for the millions of youths, pursuing to join the labor force. Therefore, current education systems must be modulated accordingly so that they could produce future graduates with appropriate technical and vocational knowledge and skills. They must gain knowledge and skills that are prerequisite to have a successful career in private sector and to protect the future generations from the menace of unemployment.

\section{Method}

This study aims to evaluate the need for expanding and elevating the vocational education sector in UAE, particularly in Abu Dhabi. It intends to assess its success level and the challenges encountered in its operations. Therefore, this study employs an explorative study design to review the need of growth of vocational education in UAE with specific reference to Abu Dhabi. The study also examines the recent efforts, undertaken in the vocational education sector in UAE and Abu Dhabi and identifies the challenges, encountered by the vocational education sector in UAE and Abu Dhabi.

Considering the national security of UAE, this paper discusses the following issues: the rate of unemployment in UAE, specifically with respect to youth living in Abu Dhabi; the existing national security challenges; the need for youth empowerment towards national security and the way forward through vocational education. The problem of security of properties and individuals in any country is essential in a sense that it does help in the capital and human development of this country.

This study offers a better insight of the TVET, given in Abu Dhabi, UAE and deals with three types of vocational systems: a dual system, school-based education and informal training. This study initially explores the motivation for these different types of training in order to emphasize the fundamental aspects of each training 
system and discuss its core strengths and challenges, before summarizing the institutional evidence. This study correspondingly reviews the evidence regarding the effectiveness of the TVET versus general education and of the three TVET systems for developing policy guideline for youth entrepreneurship.

\section{Results}

\subsection{Growth of Vocational Education in UAE}

Technical education is comparatively a new domain for the citizens of the UAE. The first school for vocational training was established in 1958 in Sharjah, where the subjects of architecture, mechanical and electrical trades were taught by the teachers, appointed by the British government. The general education was properly initiated after 1971 when the UAE came into existence (Bhattacharya, 2019). However, the vocational education was introduced and given due attention in the late 80 s when the secondary and high schools of technical education were established in the country (Al Hamad, 2020). Vocational education has been referred as a catalyst that accelerates and boosts economic growth by offering a wide range of academically competent students and skilled labor force and, thereby, eliminates poverty and unemployment (AlSuwaidi, 2016). To date, there are 73 reputable higher education institutions in the UAE, out of which vocational education and training programs are offered by 10 institutions. Approximately 18000 students have been enrolled in the schools throughout the UAE and out of which 9000 students were enrolled in the field of technical education (Global media insight, 2020). It could have been argued that the smaller number of vocational institutes in UAE comparative to other developed countries like USA and Saudi Arabia is justified as UAE comparatively have lower population. However, this argument nullifies in the light of the evidence that, New Zealand with nearly half of the UAE population have more than twice the number of institutes offering TVET (New Zealand population, 2020; Rother, 2019). Also, it has 22nd GPD (nominal) per capita rank compared to 24th rank of UAE.

The phenomenon of globalization and exponential increase in the population, have compelled the expansion of multiple sectors, including nuclear and power, oil and gas, tourism and steel and aluminum, etc. in the UAE (Hvidt, 2003). This scenario has increased the need of vocational training and education. The knowledge-based economy in UAE requires approximately 10 graduates from every university, equipped with the fundamental vocational abilities (Owais et al., 2020). Over the next decade, it is anticipated that the UAE travel and tourism industry will grow by $2.7 \%$ each year. In 2104 , this sector, contributed $8.4 \%$ in the GDP of the UAE, which is higher than that of education and financial sectors (QAA, 2017). It provides thousands of direct or indirect jobs and currently 518,000 individuals are working in this sector (Figure 1).

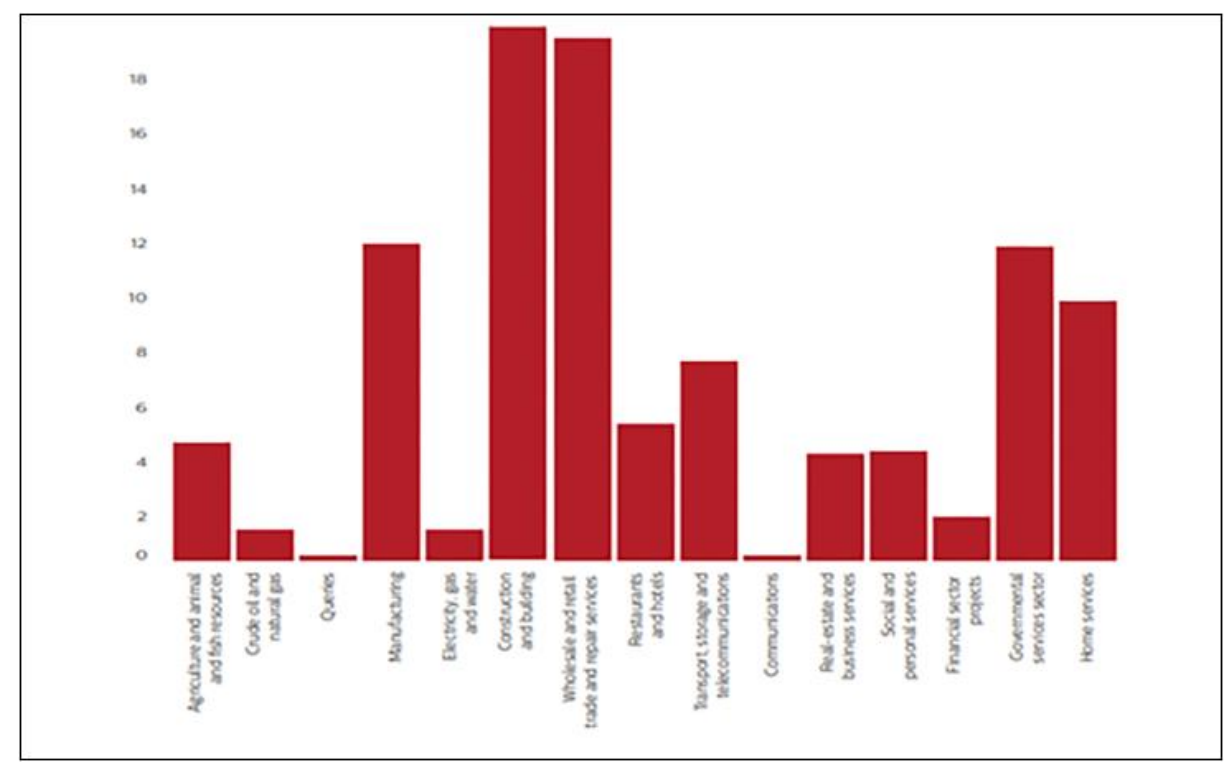

Figure 1. UAE Investment for Economic Sector (Quality Assurance Agency for Higher Education 2017)

UAE has been a fundamental player in the energy sector, with high refinery capacity, natural gas marketed production, and crude oil reserves. Moreover, over the years, the trade of oil and gas has bloomed which increased employment throughout the UAE. Growth in metal industry has been witnessed by UAE wherein new production and construction projects have been introduced for increasing the role of UAE as the dominant metal 
exporter (Schilro, 2013). Therefore, in these sectors, the job opportunities have increased for young graduates with the mandatory employability skills. However, the preferred degree of competencies and skills among the graduates needed by the subject-specific sectors is lacking (International labour office. 2010). A workforce is required in the financial sectors which must be highly qualified with appropriate education (Figure 2). A conscious point has been observed about the vocational training and courses, which indicates that the vocational education lacks in overcoming the dynamic pace of such sectors and, therefore, requires immediate attention (Miniaoui, 2017). It is essential to offer effective vocational education to the Emiratis, in order to fulfil the requirements of the UAE industry. As per the results, there is increased demand for various vocational jobs such as financial analysts, paralegals, marketing experts, software developers etc., compared to which we have very few institutes for TVET in these sectors to train our youth. Consequently, it creates shortage of experts and requires oversees hiring. Seeing the unemployment graph in UAE which indicates increase in unemployment at $2.45 \%$ in 2020 compared to record low of $1.64 \%$ in 2016, it can be said that by training youth in these sectors can solve the issue of supply and demand and also of unemployment (Pletcher, 2020).
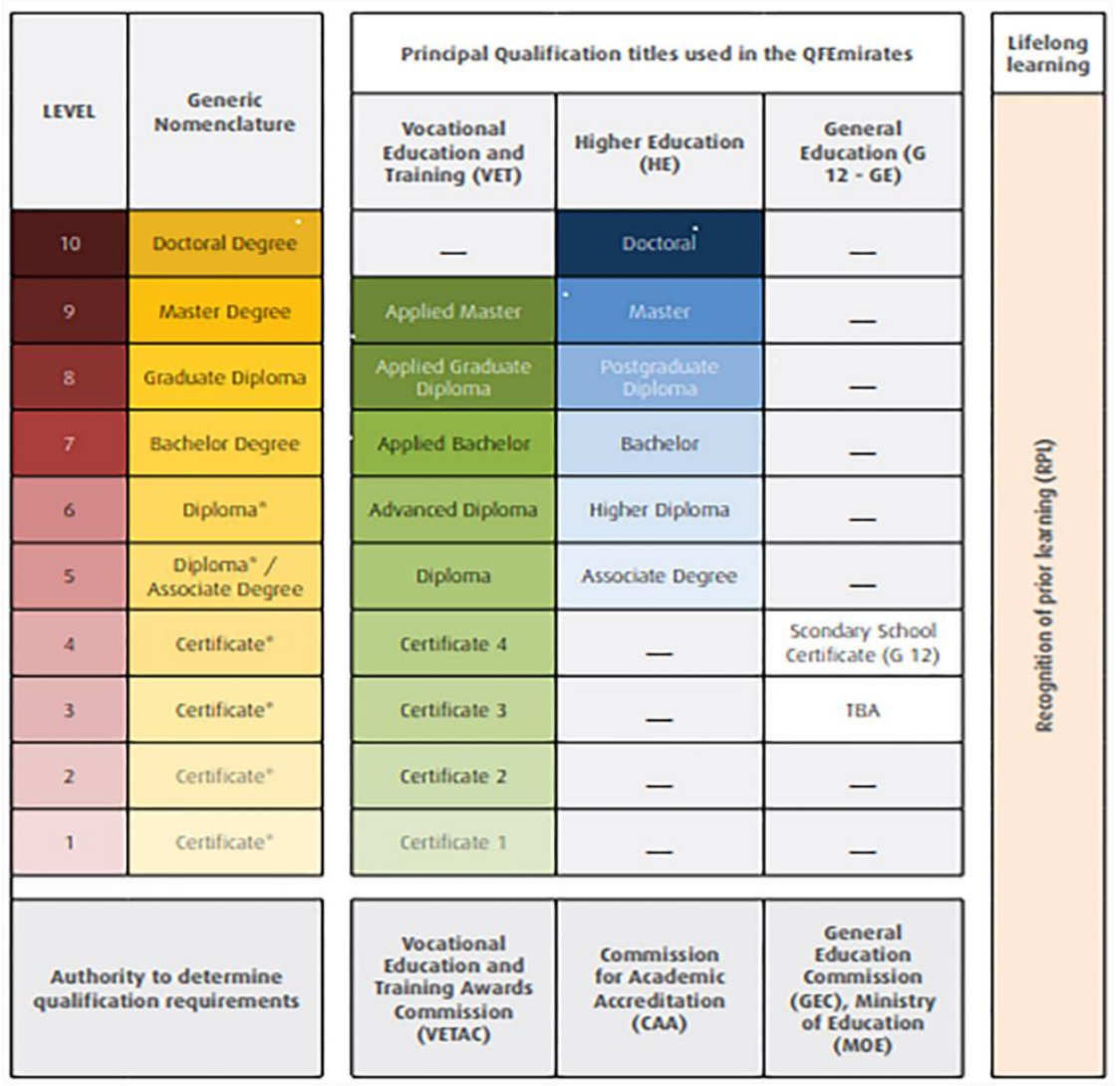

Figure 2. Principal Qualification Titles used in the QFEmirates (Quality Assurance Agency for Higher Education 2017)

National strategy has been initiated by the UAE government for the TVET with an aim to support vocational education among the individuals. It highlights on developing knowledge and skills of students while encouraging them to follow higher education. It also stresses in enhancing the quality of education to impart educational values and to ensure the accessibility of education to all who pursue it. The strategy further aims to develop efficient workforce via a plan, known as Vision 2020 (Umer et al., 2020). The emphasis here is to train the skilled workforce in the higher education institutes in order to equip them with industry-based training (Brewer and Comyn, 2015). The National Institute for Vocational Education was established by the UAE government in 2006, with a vision for developing a skilled workforce as per the requirements of the labor market consisting government, stakeholders, communities, and employers (Maclean et al., 2013).

The National Qualifications Authority (NQA) was recognized and established by the UAE government in 2010. The objective of the NQA is to produce a system that assesses high quality qualifications criteria for the nationals (Brady, 2019). This mechanism of national qualifications intends to acquire knowledge economy. It 
also intends to construct an educational framework or system consisting of vocational training that encourages the economic development with enhancements in the labor market (Shallal, 2018). The emphasis of the NQA is on developing a quality assurance process of vocational education that offers preferred outcomes, necessary to meet the social and economic needs. In this regard, the government is motivating the Emirati by integrating internationally established vocational training system (Watters, 2015) (Figure 3).

\begin{tabular}{|c|c|c|c|c|c|c|c|}
\hline \multicolumn{8}{|c|}{$\begin{array}{l}\text { Vocational Education and Iraining Awards council (VETAC) } \\
\text { Vocational Education and Iraining (VET) sector }\end{array}$} \\
\hline \multirow{3}{*}{ Qualification tité - VET } & \multicolumn{7}{|c|}{$\begin{array}{l}\text { Based on the use of two (2) kinds of interrelated } \\
\text { VET2 qualifications^ }\end{array}$} \\
\hline & \multicolumn{4}{|c|}{$\begin{array}{l}\text { ^Minimum cumulative } \\
\text { VET credit valueः for }\end{array}$} & \multicolumn{3}{|c|}{$\begin{array}{l}\text { Total notional } \\
\text { VET cumulative hours }\end{array}$} \\
\hline & $\begin{array}{l}\text { Kं்s } \\
\text { Unique } \\
\text { credits/ } \\
\text { level3 }\end{array}$ & 总 & $\frac{\frac{8}{3}}{\frac{3}{2}}$ & $\begin{array}{l}\text { Total } \\
\text { credit } \\
\text { value of } \\
\text { KSA }\end{array}$ & $\begin{array}{l}\text { Contact } \\
\text { Hours } \\
\text { KES }\end{array}$ & 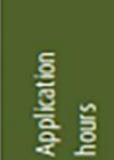 & $\begin{array}{l}\text { Total } \\
\text { KSA } \\
\text { hours }\end{array}$ \\
\hline \multicolumn{8}{|c|}{ No qualification available at this level } \\
\hline Applied Master & 10 & 200 & 18 & 218 & 3,000 & 270 & 3,270 \\
\hline Applied Graduate Diploma & 30 & 190 & 16 & 206 & 2,850 & 240 & 3,090 \\
\hline Applied Bachelor & 40 & 160 & 14 & 174 & 2,400 & 210 & 2,610 \\
\hline Advanced Diploma & 40 & 120 & 12 & 132 & 1,800 & 180 & 1,980 \\
\hline Diploma & 20 & 80 & 10 & 90 & 1,200 & 150 & 1,350 \\
\hline certificate 4 & 20 & 60 & 8 & 68 & 900 & 120 & 1,020 \\
\hline Certificate 3 & 20 & 40 & 6 & 46 & 600 & 90 & 690 \\
\hline Certificate 2 & 10 & 20 & 4 & 24 & 300 & 60 & 360 \\
\hline Certificate 1 & 10 & 10 & 3 & 13 & 150 & 45 & 195 \\
\hline
\end{tabular}

Figure 3. Qualification Title - VET (Quality Assurance Agency for Higher Education 2017)

\subsection{Status and Growth Opportunities of Vocational Education in Abu Dhabi}

The initiative of the NQA has been taken to offer high-quality and customized vocational education as per the professional standards. The VET programs are organized to train the individuals with both practical and theoretical knowledge (Ashour and Fatima, 2016). A mandatory 6-week work placement learning has been arranged by the organization and through this program, real life work experience is instilled in the students. Abu Dhabi Centre was established by the Abu Dhabi Executive Council in 2010 with an objective to introduce the process of skill development and diversifying the economy. Guidance and support are provided to the Abu Dhabi private and public TVETs by planning strategic TVET policies (Ashour and Fatima, 2016). It is also responsible to license trainers as per the standard set by the local market of the UAE. The objective of the TVET is to produce skilled Emirati who can avail greater career development and job opportunities.

Abu Dhabi Vocational Education and Training Institute (ADVETI) has recently been shifted to expand its positions, specifically since Higher Colleges of Technology (HCT) has raised its standards for admission (Swan, 2012). Students not fulfilling the criteria and standards set by the HCT are now offered admission to the ADVETI. This policy has led to a precipitous expansion of the ADVETI as it has introduced new branches in Fujairah, Ras Al Khaimah, and Sharjah. The Institute of Applied Technology was founded in 2005 by the Royal Decree which aims to provide vocational and technical education at secondary and tertiary levels. Higher learning start-ups in aviation, logistics, and nursing are included in the IAT. 
The education council of Abu Dhabi has played an important role in making efforts for enhancing vocational education in the UAE (Gonzalez et al., 2008). The education council has been given the mandate to take necessary actions throughout the Emirates, amalgamating a variety of approaches in a format that invites participation of both the private and public sectors. The seminal aspect is to elevate the ability of the universities to provide the type of vocational education that will help in fulfilling the human resource requirements of the labor market.

One specific, promising and prominent initiative for promoting vocational education is the Centre of Excellence for Applied Research and Training (CERT) which was found as a branch to the HCT in Abu Dhabi (Swan, 2012). This institution is based on international academic partnership that invests in both the multinational organizations and academic institutions, associated with business and technology solutions. These organizations and institutions pursue to promote research in the UAE, while working collaboratively. Also, they offer the essential vocational education for Emiratis. It is also imperative that Abu Dhabi is producing its much-anticipated Education and Research City, "a merger of learning comprising of primary or secondary school, college, or university, research Centre, and convention Centre with an associated five-star hotel". In fact, the objective of the Education and Research City is to produce research work of the highest quality (Heikal, 2014).

\subsection{Importance of TVET in COVID-19 Era}

In this era of COVID-19 pandemic which is not only a health and sanitary crisis affecting millions and billions of people globally, it is also a new reality for the entrepreneurs. This pandemic has turned into an unprecedented recession in global economy, where millions of people have been laid off or shutdown their businesses (Selladurai, 2017). As UAE is an oil-based economy and is highly dependent on international trade and migrant based labor, it is important to consider the implications of hit to international trade (decrease in 32\%) and international passenger traffic (63\% drop) on it (ICAO, 2020). Therefore, it warrants the need to re-strategizing the policy of Emiratization. Currently, in UAE private sector only $3.64 \%$ of employees are UAE nationals and in the total UAE workforce is only 7.62\% (Emiratisatiom rate in the private sector, 2020; Share of UAE nationals in the workforce, 2020). To the possibility of disruption in the international migration of foreign labor, this scenario could be a heavy setback for the economies like UAE that heavily depends on the foreign labor. However, this could be used as an opportunity to train the entrepreneurs for the future vocational job opportunities.

\subsection{Meta-Analysis Findings}

The effect of a TVET education program on the paid employment has been examined in majority of the studies but minimal numbers further considered their influence on self-employment and formal employment. The computation of effect sizes has been presented in the reported data for five studies and these were merged. The studies were rated as medium quality for interventions. Few of the studies were rated low. The investigation utilized the information from each study that were near to a 12-month post-training follow-up. The confidence intervals and mean effect size were presented in the forest plot for each study in Figure 4.

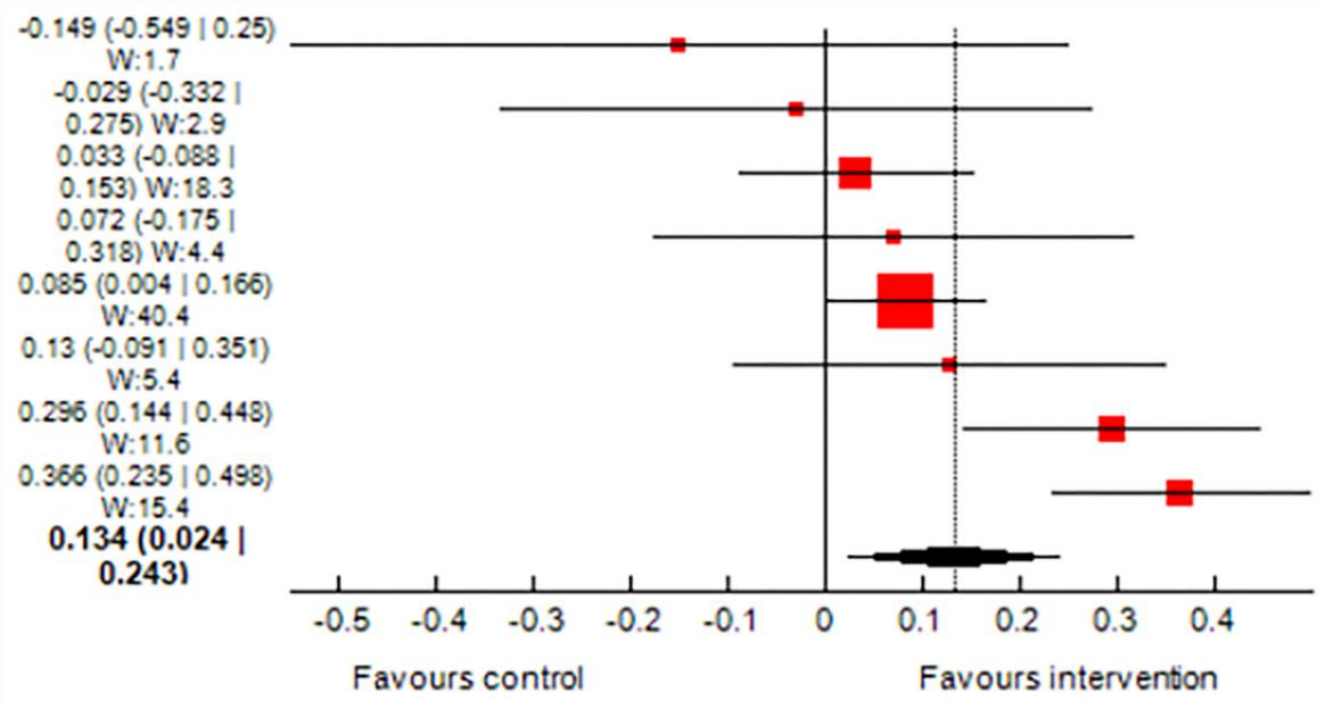

Figure 4. Forest Plot on Overall Paid Employment 
It has been indicated from the pooled estimate size that the TVET education were effective, on average, as compared to those who experienced a TVET education. It reflected an elevated opportunity of paid employment. On the contrary, differential effects across studies have been recommended from the high extent of heterogeneity between the studies $(\mathrm{Q}=27.1 ; \mathrm{df}=4 ; \mathrm{p}=0.00431 ; \mathrm{I} 2=74.1 \%$; tau2 $=0.0351)$. The first likely justification was that this review has undertaken the trend of differences, observed in the meta-analysis in terms of study quality. Independent meta-analysis was performed for low-quality studies and medium quality studies that were entered into a subgroup investigation. Figure 5 showed the mean effect size as well as confidence intervals for each study as reflected in the forest plot.

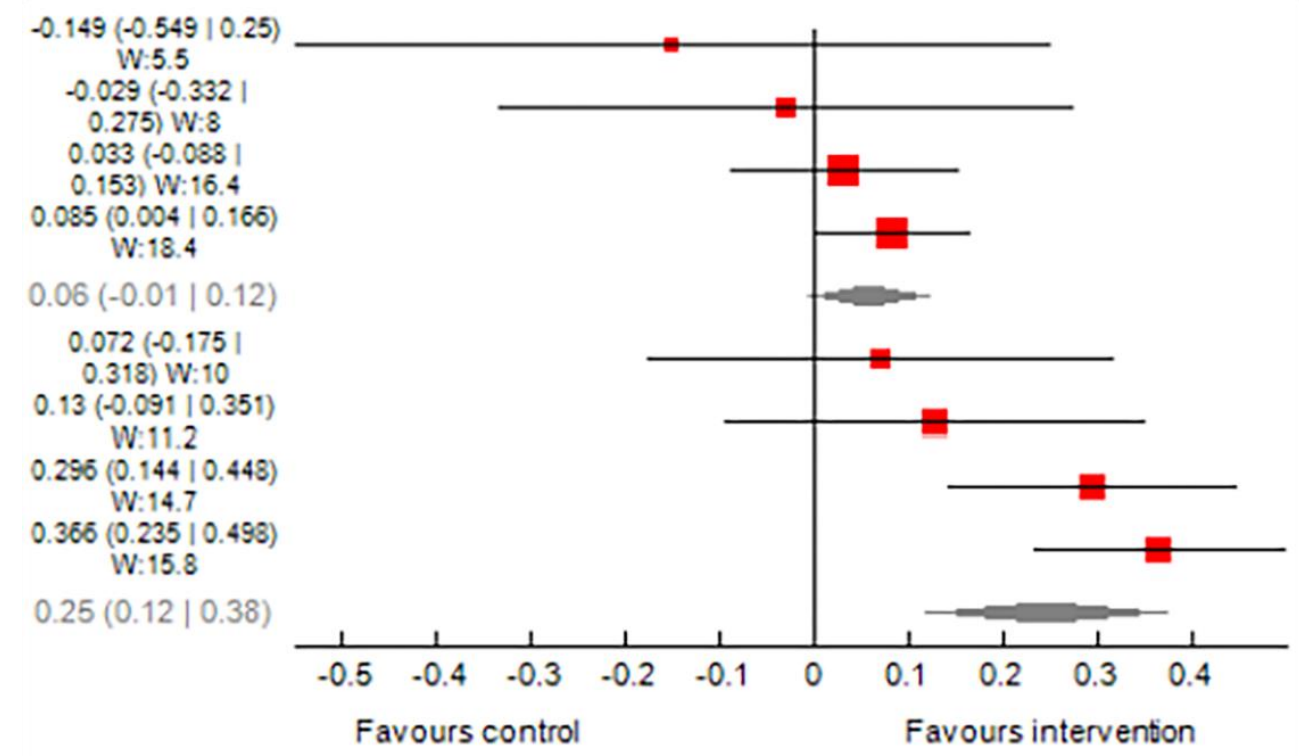

Figure 5. Forest Plot on Overall Paid Employment on the basis of Study Quality

It has been observed that the treatment effects for the low-quality studies emerged to be better as compared to those rated moderate quality. In addition, the observed differences were statistically significant in the mean effects $(\mathrm{Qb}=4.94 ; \mathrm{p}=0.0801)$. It has been indicated that mostly studies were not entailed in this review since effect sizes could not be computed for finding whether youth had participated in the TVET education, had a greater probability of being employment as compared to youth who had not participated.

Figure 4 showed the TVET education programs assessed in the five studies based on three different types. Independent meta-analysis was performed for studies consisting the TVET models and two-stage TVET interventions. Figure 6 showed the mean effect size as well as confidence intervals for each study in the form of forest plot. A weighted average effect size was identified for two-phase TVET education. The pooled estimate of effect size was positive but minimal for other TVET models. However, no negative effect was excluded from the confidence intervals. The observed differences were statistically insignificant in mean effects even though treatment effects emerged to be effective for other TVET modalities for two-phase TVET interventions. 


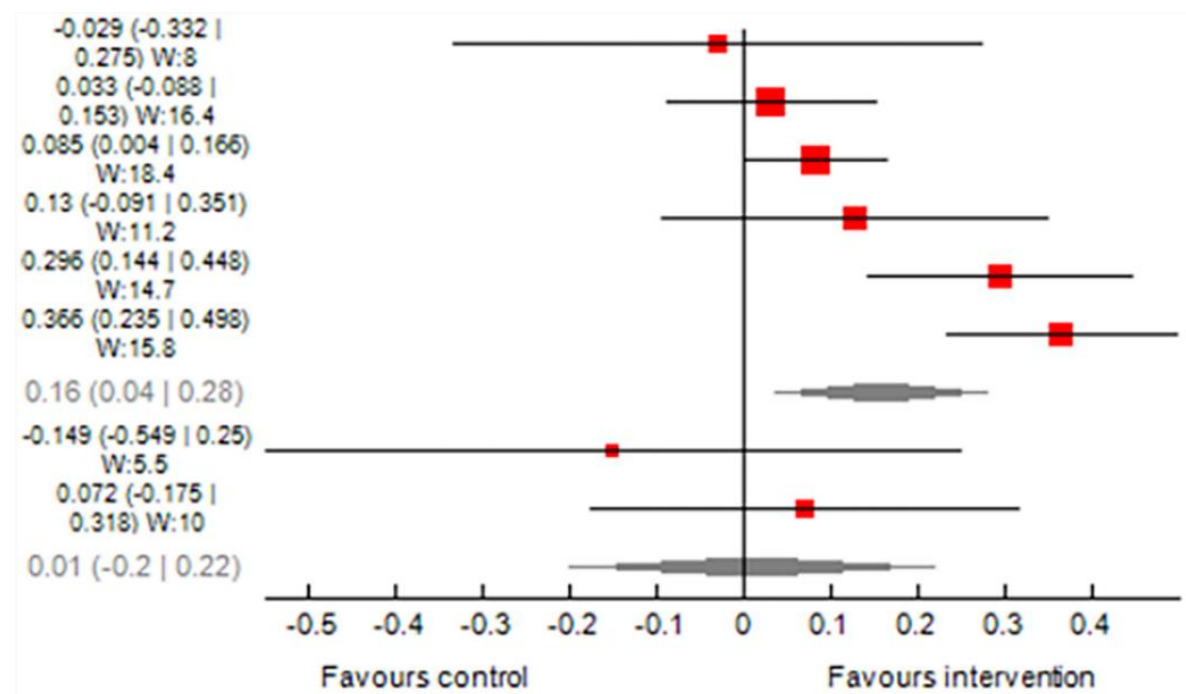

Figure 6. Forest Plot based on Program Type

The effect of the intervention was evaluated in four out of five studies included in the meta-analysis, after training had ended either around 12-15 months or at almost 6 months. Effects have been examined in the remaining studies, in order to measure outcomes at 6, 12, and 18 months. Independent meta-analyses were performed for studies consisting of medium-term and short-term follow-up periods. These meta-analyses were then included into a sub-group analysis. Figure 7 presents the mean effect size as well as confidence intervals for each study in the form of forest plot. It has been observed that short-term treatment effects were greater as compared to moderate effects. On the contrary, the observed differences were not statistically significant in mean effects. The differences remained insignificant when the sub-group was reperformed.

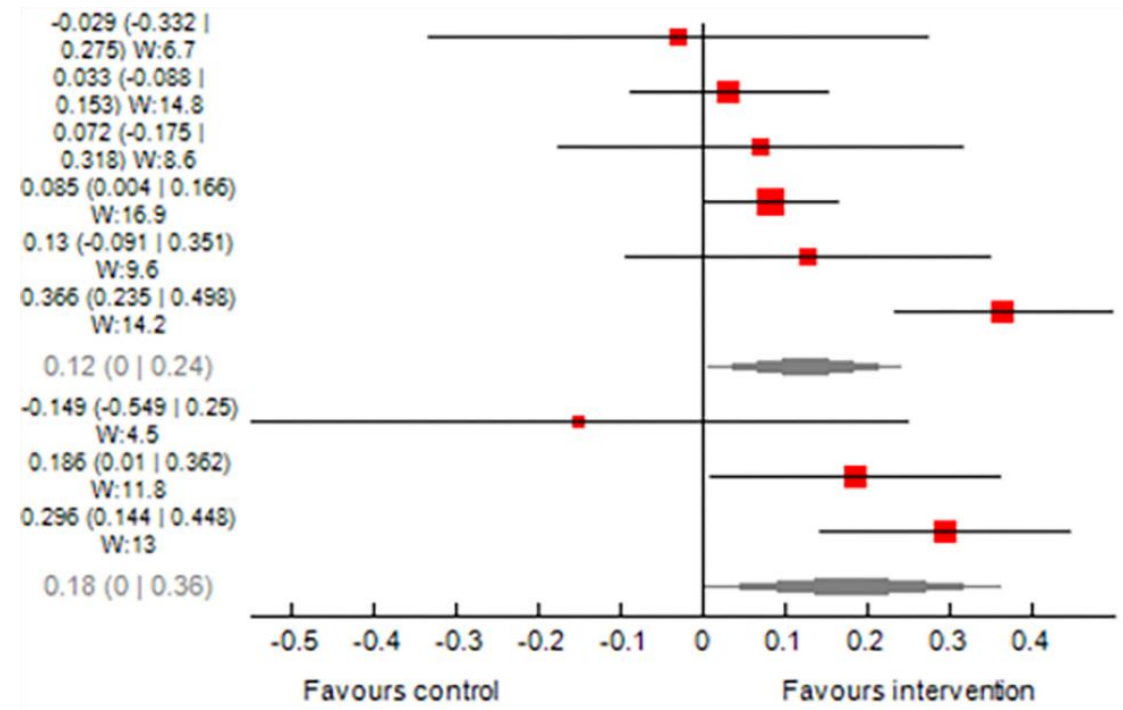

Figure 7. Forest Plot with respect to Length of Follow-up

The information from the four studies were agreeable to meta-analysis. The studies were rated of moderate quality. Few of the studies were rated of low quality. Independent meta-analyses were performed for studies consisting of data with different gender structures. These data were then entered into a sub-group analysis. Figure 8 shows the mean effect size as well as confidence intervals for each study as represented in the forest plot. It has been observed that treatment effects were slightly greater for female youth as compared to male youth. On the contrary, the observed differences were not statistically significant in mean effects. The differences 
remained insignificant when the sub-group examination was reperformed with merely those medium-rated studies. It has been observed that one of the three studies examining differences observed regional variation when affected by location. Two of the three studies found greater positive effects for educated workers as compared to the less education, when explored treatment effect heterogeneity in terms of education.

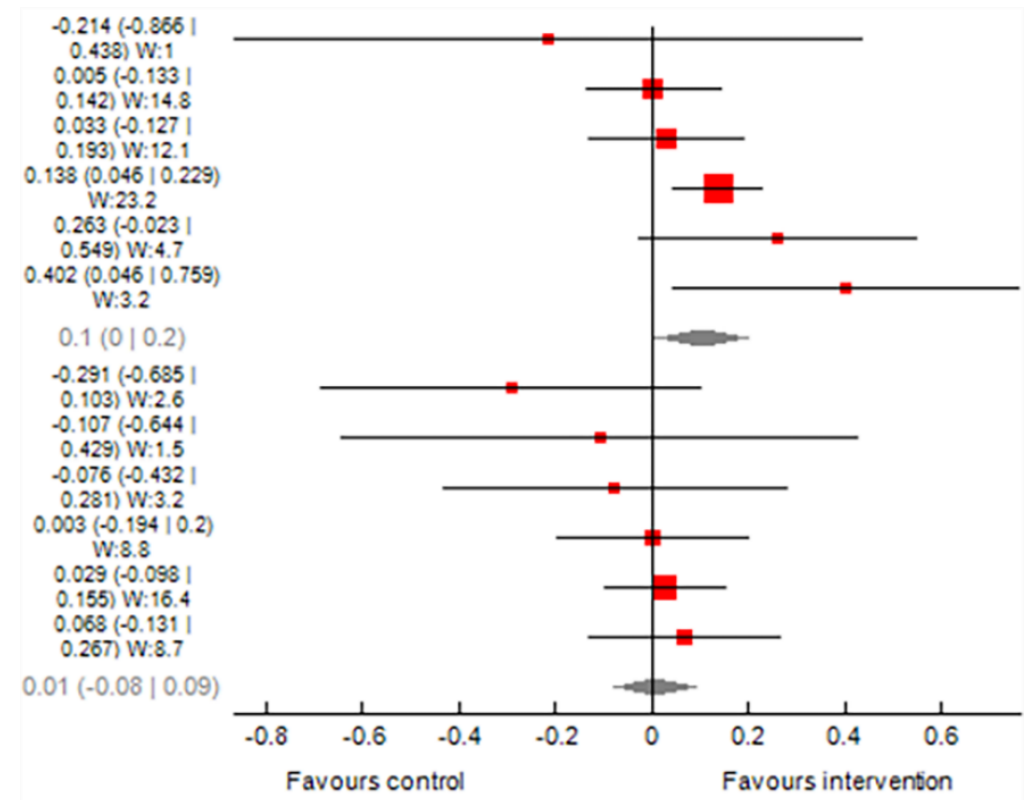

Figure 8. Forest Plot with respect to Length of Gender

\section{Discussion}

This review has examined the promising roles of the TVET education and training in empowering youth, based on their entrepreneurial skills in the UAE. This review, based on explicit search included 20 studies for published and unpublished studies. The TVET opportunities were provided to youth in 12 out of 20 studies. Using more of the findings from the 12 studies needs further resources after including them more explicitly into the synthesis. In this regard, it would be early for indicating that the data selected from such studies supported the findings from the meta-analysis on the basis of the evaluation of the examined direction of effects. This summary of evidence and the conclusions drawn about 'what works, and emphasizes merely on the findings of the statistical investigation of the 12 studies. The approach used in this study to summarize the evidence, particularly establishes the foundation to identify implications for policy and practice. The overall mean effect of the TVET was positive and significant on paid employment $(\mathrm{g}=0.431,95 \% \mathrm{CI}[0.014,0.631])$. On the contrary, significant heterogeneity was also observed $(\mathrm{Q}=27.1 ; \mathrm{df}=4 ; \mathrm{p}=0.00431 ; \mathrm{I} 2=74.1 \%$; tau2 $=0.0351)$.

It is justifiable to explain that the overall mean effect might be magnified and that conclusions regarding treatment effect on paid employment, must be based merely on the medium rated quality, since there is an evidence of statistically significant association between effect size and study quality. The mean estimate for such studies is non-significant and minimal. It is observed that there is merely minimal evidence that the TVET interventions are effective in order to elevate the possibility to have paid employment for young people, on average. In addition, the observed effect was very minimal.

Entrepreneurship is an essential objective of lifelong learning. Learning possibilities and courses must be available then since majority of entrepreneurs commence their own business or become self-employed in later stages of life (Paryono, 2017). This requires focused, just-in-time and tailor-made training as well as knowledge sharing. Various levels and types of firms require a differentiated approach. Training and learning support must emphasize on market analysis, maintaining and building networks besides organizational and management skills (Aldossari, 2020). A learning experience is provided on both sides by offering together business school students. Particular concentration must be offered to beginners with a low educational status. Entrepreneurship is an option for low achievers at schools and groups can be supporting. For instance, immigrants desire to commence their own firm, studio, or shop (Alyani \& Guile, 2017). Adversely educated individuals consist of up to $40 \%$ beginners in industry. In addition, a comparatively large number of low-educated starters were experienced in the 
retail trade. Therefore, this shows the need for preparation for entrepreneurship at lower vocational educational levels (Orbeta Jr, 2016).

Alghizzawi et al. (2019) identified some of the major advantages of e-learning, as it delivers education in the virtual environment by the inclusion of different devices which include; mobile phones, personal computers, and tablets (Salloum \& Al-Emran, 2018; Salloum et al. 2019). This virtual learning method help teachers and students in providing access to course contents in digital form, share knowledge, while making learning more effective with increased interaction among teachers and learners through online forums, knowledge and content sharing. These platforms stimulate learning through different features which includes, development of online courses, evaluation and monitoring of activities for students and teachers (Alghizzawi et al., 2019). Araújo Júnior and Marquesi (2009) further added that e-learning methods such as LMS help in enabling a synchronized communication, by promoting the use of different strategies while promoting a dialogue and students' active participation. In relation to the assessment methods employed in e-learning systems, Rahrouh, Taleb \& Mohamed (2018) added that LMS in general has been effective, usable, efficient, manageable, and reliable. The respondents further showed a positive attitude towards the use of LMS and its effectiveness in students' assessment. While, Yilmaz (2017) identified some of the commonly used techniques in the online assessment of students in virtual learning.

The major contribution of this study was its application of systematic review principles for enhancing on previous work. On the contrary, there are several limitations to this review that must be considered for future studies. Firstly, effect sizes for 12 of the 20 included studies were calculated. Thereby, the meta-analysis of quantitative findings encompasses more than half of the studies, entailed in the review. The estimated pooled effect might not be the effect of all the studies, encompassed in this review. Its reason can be stated as if the studies were possible for computing effect sizes, which were different. In addition, the exclusion of eight studies may have influenced the strength of the meta-analysis, restricting the probability to detect significant programming effects. Secondly, publication bias was minimized by performing an extensive literature search. It might be possible that all eligible studies could not be identified. Surprisingly, the minimal number of studies may impair any significant quantitative publication bias examination for which effect size calculation was possible that would have enriched the discussion on the presence of publication bias in studies evaluating the TVET education.

Thirdly, the methods to compute comparable effect sizes were under-developed and need additional research as previous studies were based on complicated econometric methods. Lastly, effect sizes were synthesized in this meta-analysis from a broader perspective of methodological designs, which included quasi-experimental and experimental designs. Some of the methodological issues were related with the lower quality of some quasi-experimental studies, which indicated that the studies have possessed biased estimates of the treatment effects such as those utilizing propensity score matching.

\subsection{Implications}

Entrepreneurial skills play an immense role in bringing about social and economic shift. Entrepreneurship education was put forth as an essential phase in the advancement of the TVET institutions in UAE. It was also observed an essential role in empowering youth that can generate positive outcomes. This study is very important as it offers insight into some of the entrepreneurship education practices of the TVET platform. A lack of entrepreneurship education in the UAE is revealed from the information shared.

This study has revealed a number of areas that are lacking about entrepreneurship education. Another essential advancement was interest of students for seeking entrepreneurship education, which was substantially high and majority of the students had an interest in seeking entrepreneurship education. The extent and availability of entrepreneurship education are non-existent in majority of the cases. The preference from students shows that placing entrepreneurial skills and education can be of substantial value to them with the TVET curricula. The perception of support and benefits shared perceptive concepts, regarding their significance to offer entrepreneurship education. Considering the role of support and benefits, it has to be valued with respect to provide entrepreneurship education. The results from this study offer a better opportunity for the TVET institutions for embracing and utilizing the information for sharing their practices.

There is an elevating international interest in the TVET as a means to advance sustainable development and to address social and economic challenges. This review was undertaken for supporting policy-level organizations, donors, and foundations, and departments for taking actions and developing policies for improving labor market findings for youth in the UAE. The findings of this review strengthen the evidence, base on which existing policies and strategies can draw. It enhances upon previous work by statistically synthesizing the TVET 
intervention. Therefore, interpreting the evidence and drawing out the implications is nonetheless challenging for policy and practice.

\section{References}

Abhyankar, R. (2014). The government of India's role in promoting innovation through policy initiatives for entrepreneurship development. Technology Innovation Management Review, 4, 8. https://doi.org/10.22215/timreview/818

Al Hamad, M. (2020). Exporting Finnish vocational education and training to the United Arab Emirates: opportunities and challenges. Retrieved from https://www.theseus.fi/bitstream/handle/10024/343502/Al\%20Hamad_Muntaser.pdf?sequence=2\&isAllowe $\mathrm{d}=\mathrm{y}$

Al Hammadi, A. R. J. (2016). An Overview - Indicators of the Vocational Education Sector in UAE. International Journal of Scientific \& Engineering Research, 7, 2229-5518.

Al Hammadi, A. R. J., \& Mohiuddin, S. S. (2017). Growing trends of the vocational education in UAE. International Journal of Scientific Engineering and Research (IJSER), 2347-3878. Retrieved from https://pdfs.semanticscholar.org/d937/2e1ec1787542f9bd4e11852356814c4ce2f6.pdf

Aldossari, A. S. (2020). Vision 2030 and reducing the stigma of vocational and technical training among Saudi Arabian students. Empirical Research in Vocational Education and Training, 12, 1-24.

https://doi.org/10.1186/s40461-020-00089-6

AlefEducation, "Engaged learning."

Alghizzawi, M., Habes, M., Salloum, S. A., Abd, M., Ghani, C. M., \& Shaalan, K., (2019). The effect of social media usage on students'e-learning acceptance in higher education: a case study from the United Arab Emirates. International Journal of Information Technology, 3(3), 13-26.

AlMunajjed, M., \& Sabbagh, K. (2011). Youth in GCC countries: meeting the challenge. Booz \& Company Inc, Retrieved from https://www.effentiicorp.com/wp-content/uploads/2014/08/Strategyand-GCC-Youth-Challenge.pdfAl

Alyani, N., \& Guile, D. (2017). Learning to Innovate by Connecting Interprofessional Judgement-Exploring the Digitised Creative Sector in the Gulf. In Vocational Education and Training in Times of Economic Crisis (pp. 83-105). Springer, Cham. https://doi.org/10.1007/978-3-319-47856-2_5

Asadullah, M. A., \& Ullah, A. Z. (2018). Social-economic contribution of vocational education and training: an evidence from OECD countries. Industrial and Commercial Training, 50, 172-184. https://doi.org/10.1108/ICT-12-2017-0100

Ashour, S., \& Fatima, S. K. (2016). Factors favoring or impeding building a stronger higher education system in the United Arab Emirates. Journal of Higher Education Policy and Management, 38(5), 576-591. https://doi.org/10.1080/1360080X.2016.1196925

Badry, F. (2019). Expanding the UAE's Higher Education Horizon: Path Toward a Sustainable Future. Education in the United Arab Emirates. Springer, Singapore. https://doi.org/10.1007/978-981-13-7736-5_4

Bhattacharya, P., \& Nakhare, S. (2019). Exploring AI-enabled intelligent tutoring system in the vocational studies sector in UAE. In 2019 Sixth HCT Information Technology Trends (ITT). IEEE, 230-233. https://doi.org/10.1109/ITT48889.2019.9075093

Brewer, L., \& Comyn, P. (2015). Integrating core work skills into TVET systems: Six country case studies. Geneva: ILO [International Labour Organization]. Retrieved from https://www.ilo.org/wcmsp5/groups/public/---ed_emp/---ifp_skills/documents/publication/wcms_470726.pd $\mathrm{f}$

Emiratisation Rate in The Private Sector. (2020). Default. Retrieved from https://www.vision2021.ae/en/national-agenda-2021/list/card/emiratisation-rate-in-the-private-sector

Global Media Insight. (2020). United Arab Emirates Population Statistics. Retrieved from https://www.globalmediainsight.com/blog/uae-population-statistics/

Goel, V. P., \& Vijay, P. (2011). Technical and vocational education and training (TVET) system in India for sustainable development. Bonn, UNEVOC. Retrieved from https://eksis.ditpsmk.net/uploads/book/file/A17B3F28-7A86-42D0-9407-287A885083B7/India_Country_P 
aper.pdf

Gonzalez, G., Karoly, L. A., \& Constant, L. (2008). Facing human capital challenges of the 21st century: Education and labor market initiatives in Lebanon, Oman, Qatar, and the United Arab Emirates (Vol. 786), Rand Corporation, Qatar. https://doi.org/10.7249/MG786

Government of India. (1992). National Policy on Education 1986 (as modified in 1992). Retrieved from https://web.archive.org/web/20101126024709/http://education.nic.in/policy/npe86-mod92.pdf

Heikal, M. M. (2014). Evaluating the Outcomes of Vocational Education Program in Abu Dhabi from a Project Management Perspective (Doctoral dissertation, The British University in Dubai (BUiD)). Retrieved from https://bspace.buid.ac.ae/handle/1234/659

Hvidt. (2013). Economic diversification in GCC countries: Past record and future trends. Retrieved from http://eprints.lse.ac.uk/id/eprint/55252

ICAO. (2020). Economic Impact Estimates Due To COVID-19 Travel Bans. Retrieved from https://www.icao.int/Newsroom/Pages/Economic-impact-estimates-due-to-COVID-19-travel-bans.aspx

International Labour Office. (2010). A skilled workforce for strong, sustainable and balanced growth: a G20 training strategy. Retrieved from http://hdl.voced.edu.au/10707/2719

Jose, S., \& Chacko, J. (2017). Building a sustainable higher education sector in the UAE. International Journal of Educational Management, 31(6), 752-765. https://doi.org/10.1108/IJEM-05-2016-0102

Maclean, R., Jagannathan, S., \& Sarvi, J. (2013). Skills development for inclusive and sustainable growth in developing Asia-Pacific. Springer Nature, New York. https://doi.org/10.1007/978-94-007-5937-4

Miniaoui, H., \& Schilirò, D. (2017). Innovation and entrepreneurship for the diversification and growth of the gulf cooperation council economies. https://doi.org/10.11114/bms.v3i3.2594

New Zealand Population. (2020). Worldometer, 2020. Worldometers.Info. Retrieved from https://www.worldometers.info/world-population/new-zealand-population/

Orbeta Jr, A. C. (2016). The national system of technical vocational education and training in the Philippines: a review and ideas for reforms. Protection and training: Institutions for improving workforce integration in Latin America and Asia. Santiago: ECLAC, 2016. LC/G. 2687, 357-390. https://doi.org/10.18356/76e50b23-en

Owais, A., Alabidi, S., Hatamleh, Z., \& Hussein, E. (2020). Technical and Vocational Education and Training in the UAE. International Journal of Emerging Technologies in Learning (iJET), 15(13), 264-288. https://doi.org/10.3991/ijet.v15i13.13801

Paryono. (2017, September). The importance of TVET and its contribution to sustainable development. In AIP Conference Proceedings (Vol. 1887, No. 1, p. 020076). AIP Publishing LLC. https://doi.org/10.1063/1.5003559

Plecher, H. (2020). United Arab Emirates - Unemployment Rate 2020. Statista. Retrieved from https://www.statista.com/statistics/297778/uae-unemployment-rate/\#: :text=In\%202020\%2C\%20the\%20un employment\%20rate,available\%20and\%20actively\%20seeking\%20employment

Quality Assurance Agency for Higher Education (Great Britain) (QAA). (2017). Country report: The United Arab Emirates. Retrieved from http://hdl.voced.edu.au/10707/441609

Rahrouh, M., Taleb, N., \& Mohamed, E. A. (2018). Evaluating the usefulness of e-learning management system delivery in higher education. International Journal of Economics and Business Research, 16(2), 162-181. https://doi.org/10.1504/IJEBR.2018.094010

Raven, J. (2011). Emiratizing the education sector in the UAE: contextualization and challenges. Education, Business and Society: Contemporary Middle Eastern Issues. https://doi.org/10.1108/17537981111143864

Ridge, N., Kippels, S., \& ElAsad, S. (2015). Education in Ras Al khaimah and the United Arab Emirates. Retrieved from https://1stdirectory.co.uk/_assets/files_comp/e8f64f46-034b-4868-ae48-2c39ccd11ac8.pdf

Rother N. (2019). Hands-on: new suggestions to reform the vocational sector in New Zealand. Retrieved from https://apo.org.au/sites/default/files/resource-files/2019-08/apo-nid258646.pdf

Salloum, S. A., \& Al-Emran, M., (2018). Factors affecting the adoption of e-payment systems by university students: extending the TAM with trust. International Journal of Electronic Business, 14(4), 371-390. https://doi.org/10.1504/IJEB.2018.098130 
Salloum, S. A., Al-Emran, M., Khalaf, R., Habes, M., \& Shaalan, K. (2019). An innovative study of e-payment systems adoption in Higher Education: theoretical constructs and empirical analysis. International Journal of Interactive Mobile Technologies (iJIM), 13(06), 68-83. https://doi.org/10.3991/ijim.v13i06.9875

Schiliro. (2013). Diversification and development of the UAE's economy. Retrieved from https://mpra.ub.uni-muenchen.de/id/eprint/47089

Schwanen, D. (2017). Innovation Policy in Canada: A Holistic Approach. CD Howe Institute Commentary, 497. https://doi.org/10.2139/ssrn.3088156

Selladurai, M. (2020). Evolution of technopreneurial entrepreneurs in the Covid-19 pandemic situation. Research Explorer-A Blind Review \& Refereed Quarterly International Journal, 8(29), 2349-1647.

Shallal, M. A. (2018). Trends in undergraduate program curriculum frameworks. Academic Journal of Nawroz University, 7(3), 228-234. https://doi.org/10.25007/ajnu.v7n3a229

Share of UAE Nationals in The Workforce. (2020). Default. Retrieved from https://www.vision2021.ae/en/national-agenda-2021/list/card/share-of-uae-nationals-in-the-workforce.

Suwaidi, H. (2016). Technology-Enhanced Learning, Reflective Practices and Collaborative Learning for a Better Employability of Vocational Education Students in the UAE. Retrieved from http://hdl.handle.net/11599/2510

Swan, M. (2012). Thousands turn up at Abu Dhabi vocational college. The National News. Retrieved from http://www.thenational.ae/news/uae-news/education/thousandsturn-up-at-abu-dhabi-vocational-college

Umar, T., Egbu, C., Ofori, G., Honnurvali, M. S., Saidani, M., Shibani, A., Opoku, A., ... Goh, K. (2020). UAE's commitment towards UN Sustainable Development Goals. In Proceedings of the Institution of Civil Engineers-Engineering Sustainability, 1-19. https://doi.org/10.1680/jensu.19.00036

Vixathep, S. (2017). Entrepreneurship, human and social capital, and government policy in small and medium enterprise development in Laos. Japan Social Innovation Journal, 7(1), 33-50. https://doi.org/10.12668/jsij.7.33

Watters, E. (2015). Promoting Quality Assurance in Vocational Education and Training: the ETF Approach. ETF Working Paper. European Training Foundation.

Wilkins, S. (2002). Human resource development through vocational education in the United Arab Emirates: the case of Dubai polytechnic. Journal of Vocational Education and Training, 54(1), 5-26. https://doi.org/10.1080/13636820100200190

Yilmaz, R. (2017). Problems experienced in evaluating success and performance in distance education: a case study. Turkish Online Journal of Distance Education, 18(1), 39-51. https://doi.org/10.17718/tojde.285713

\section{Copyrights}

Copyright for this article is retained by the author(s), with first publication rights granted to the journal.

This is an open-access article distributed under the terms and conditions of the Creative Commons Attribution license (http://creativecommons.org/licenses/by/4.0/). 